\title{
CJAR
}

Canadian Journal of Action Research Volume 20, Issue 2, 2020, pages 85-103

\section{PROJECTS WITH PEOPLE, PARTICIPANT-COERCION AND THE AUTOETHNOGRAPHICAL INVITE}

\author{
John Freeman \\ University of Huddersfield \\ West Yorkshire, England
}

\begin{abstract}
Researchers in the arts and social sciences often work on multiple projects simultaneously; we are by definition highly social in our professional and outreach relationships. Working in the field of drama, with its innate focus on people and communities, multiplies this social aspect. Qualitative approaches such as action research and autoethnography are regularly employed in arts and education practices. This article describes a long-term relationship with a not-forprofit organisation in the UK, focusing on a project that used drama as a tool for building selfconfidence and employability. At the same time, it attempts to link autoethnography with participatory action research, describing some of the distinctive features and questioning the relationship between empathy and exploitation, informed consent, and participantmanipulation. This aspect is couched in terms of a journey that interrogates the insider/outsider status of researchers. Where the article asks questions, these are significantly, if not always exclusively, asked of its writer; where it becomes a troubled and potentially troubling ethical calling to account, it is this writer who most overtly stands accused. Readers are invited to journey through documentation that at times doubts its own place; through an article which questions some taken-for-granted research practices and which navigates the personal/professional tensions in conducting research with participants.
\end{abstract}

KEYWORDS: Action Research, Autoethnography, Research, Narrative writing, Empathy, Exploitation, Dissemination, Drama, Informed consent, Participant-coercion.

\section{ETIQUETTE, ETHICS AND DECLARED SELF-INTEREST}

Qualitative approaches such as action research and autoethnography are regularly employed in arts and education practices. This article describes a long-term relationship 
with a not-for-profit organisation in the UK, focusing on a project that used drama as a tool for building self-confidence and employability. At the same time, this article attempts to link autoethnography with participatory action research, describing some of the distinctive features and questioning the relationship between empathy and exploitation, informed consent, and participant-manipulation. This aspect is couched in terms of a journey that interrogates the insider/outsider status of researchers.

Where the article asks questions, these are significantly, if not always exclusively, asked of its writer; where it becomes a troubled and potentially troubling ethical calling to account, it is this writer who most overtly stands accused. Readers are invited to journey through documentation that at times doubts its own place; through an article which questions some taken-for-granted research practices and which navigates the personal/professional tensions in conducting research with participants.

The temptation is to follow a type of assumed etiquette that comes with conventional academic articles, reporting that I conducted a qualitative action research study in order to understand the challenges, needs, and situation of a group of young people who had been either excluded from full-time learning, were long-term unemployed, or had a history of criminal behaviour. I would write further that these young people are aware that this article is being written. A further temptation is to describe the ways that this article will be of benefit to its readers.

This article does not quite give in to this temptation. The result is a kind of push-me/pullyou contradiction that threatens to turn one thing into another, morphing work intended to benefit participants involved in a project into an article designed to provide benefit to an entirely different group of people. The article goes further still into questioning the ethics of constructing a report that potentially exploits the group of its original participants. In doing so, the following words, peppered as they are with self-questions, asks what is not generally asked about the temptation to turn one thing into another and about the relationship between participant consent and coercion. I should stress at this early stage that the coercion I speak to relates to my own practice rather than anything imposed on me. I am fortunate enough to feel no sense of coercion on the part of the two universities I am associated with, each of which is forward-thinking in terms of the role and significance of what we might refer to as scholar artists or of outputs that are other than written, refereed and published. Inasmuch as I feel no pressure to publish, and given that I have doubts as to whether or not I should write publicly about work that took place in private, the obvious question is why write this article at all?

This is an article about the possibility of writing about the project, the words are an attempt to exercise self-doubts through what amounts to a form of critical catharsis; a process of reflection that allows me to put my own experiences within a frame that might strike a chord with other people, turning anxiety over purpose into something constructive. The article responds to my need to become a more reflective practitioner, to present a critical response to my experience as practitioner/teacher and scholar/researcher. Through this inquiry, I am searching for a means of re-examining the experiences of doing 
and subsequently writing about, benefiting my ongoing practice and highlighting both the advantages and potential problems of narrative methods of inquiry and self-reflection. Where I draw on autoethnography I do so in line with the idea that it is a form of "action research for the individual" (Ellis \& Bochner, 2000, p. 754). In telling stories of experiences in the form of an article, I inevitably reflect on those experiences and try to make meaning of them.

Workshops are always participatory. There are multiple ways we can approach research, which is participatory, just as there are multiple ways of positioning ourselves as researchers. The question this article asks above all else is what do I do now that I have all of this information, documentation and lived experience through the project? Can I, in anything approaching good conscience, change what was participatory into something that is singular and in some ways self-serving?

\section{EITHER/OR ... NEITHER/NOR: ACTION RESEARCH, AUTOETHNOGRAPHY AND NAMING}

I am engaging here in a laboratory of awareness (Jousse, 2000, p. 27) in which "the experimenter is simultaneously the experimented... The true Laboratory is therefore the Laboratory of the self. To instruct oneself is to develop oneself." (Jousse, 2000, pp. 2627). Throughout the article, I am working with what I have experienced directly (Sienaert, 1990, p. 2). At the same time, the article is an attempt to exercise a series of questions. I identify with Ross Mooney's (1957) assertion that research is a venture, which is worth doing for its direct contribution to one's own self-realisation. Accordingly, I make meaning of my lived experiences as a learner and teacher, exploring approaches that enable me to know myself through practice and, conversely, perhaps, to doubt myself in print. Jousse (2000) reminds me that I am in a position to identify who I am in relation to others and that I should exercise the willingness to articulate approaches that enable new thoughts to develop; thoughts and understandings that empower other people to improve their work for the beneficiaries in their care.

I am drawn to autoethnography as a research method through which researchers can explore the culture where a phenomenon is being experienced. Because we are all actors in the contexts in which we interact, attempting to tell the 'truth' of any exercise through autoethnography is an impossible aim; nevertheless, it can help us to better understand a phenomenon in a given community or setting (Flick, 2009). Autoethnography allows me to draw on experiences to understand a particular phenomenon. Where this article utilizes elements of telling my personal story it does so in order to help me reflect on my approach to learning and research and empathise with my participants' experiences and reactions. As emphasised by Barkhuizen and Wette (2008), there are different uses of the term 'autoethnography' and these shift according to the relations between the researcher's personal experience and the phenomenon under investigation, ranging from research about personal experiences of a process to exploration of the participants' experiences and about the experience of the researcher while conducting a specific piece of research (Ellis and Bochner, 2000; Maso, 2001). For Méndez and Peña (2013) analytic autoethnography is directed towards objective writing, whereas evocative autoethnography aims toward 
researchers' introspection on a particular topic to allow readers to make a connection with the researchers' feelings and experiences. For the purposes of this article, analytical language is used at times to describe moments that seek evocation and resonance. In this hybridity, the purposes of autoethnography become as diverse as the topics they deal with. Autoethnography is a suitable companion to participatory research inasmuch as it foregrounds the emotions required to describe human experience (Cresswell, 2007). Built as it is around story, autoethnography is a useful device for integrating the contextual background of a personal journey, focusing on the researcher's role within a particular cultural group. As Toledano and Anderson (2017) and Darby (2017) remind us, this type of personal narrative is not easily distinct from participatory action research where reflection occurs to inform, albeit not necessarily improve, subsequent actions.

Wilfred Carr and Stephen Kemmis (1986) saw action research as "a form of self-reflective enquiry undertaken by participants in social situations in order to improve the rationality and justice of their own practices, their understanding of these practices, and the situations in which the practices are carried out" (p. 210). The collaborative element of participation was central to the UK project; nevertheless, I can reasonably ask at what point data made up of authoethnographic vignettes becomes the legitimate basis for a subsequent research account. When what amounts to a friendship group working together and commenting upon each other's stories is reverse-engineered into a form of discourse analysis. As I focus on the action of self in relation to other people, I will be revealing my professional identity and knowledge (Hamilton, Healy, Dunstan, Zderic, \& Owen, 2008; Pithouse, Hall, Peckover \& White, 2009). In the process of solitary writing, I hold to the idea that I "do not construct practice alone" (Hamilton and Pinnegar, 2009, p. 15).

I situate myself in my study as an insider, an implicated insider and observer (Jousse 2000; Stoller, 1997) as I "understand, facilitate and articulate the teaching-learning process" from the perspectives of and through my lived experiences (Whitehead, 2004, p. 876). This is "an holistic approach that acknowledges the intersection of the personal and professional... lead(ing) to reflective critique and a concern about change, social justice and professional action" (Pithouse et al., 2009, p. 58). I use Clandinin and Connelly's (2006) definition of autoethnography in which personal narrative "is a portal through which a person enters the world and by which their experience of the world is interpreted and made personally meaningful" (p. 376) alongside the view offered by Pennebaker et al. (1999) that action research is "a systematic research process that can be articulated by the researcher, involving ... reflection and discussion with co-researchers or others for the purpose of making change in a situation over time" (p. 1251). There was considerable participant agency in the workshops, and some evidence of change. Participants were actively and consciously engaged in reflecting and deciding individually and collectively on the next steps in our unfolding journey carried out with the organisation in question.

The organisation, Motorvate UK, is a training provider based in Coventry, offering bespoke courses in trade areas that enable young people to explore different skills and progress to further education or employment. These young people are often disengaged from education or on the verge of exclusion with very low academic achievements. The 9th 
largest city in England and the 12th largest in the UK, Coventry has high levels of unemployment and crime. The area has always welcomed immigrants of all nationalities, significantly from Irish communities, the Indian-sub continent and West Indian communities, which settled in the mid-20th century. More recently, a wave of new immigrants from Northern Iraq and Iran as well as people from African nations and Eastern Europe have settled and invested in the city. In an early nod to the lure of autoethnography, I should say that I grew up in Coventry, having moved there from the south coast of England as a child, that I too was excluded from school and that my academic achievements-until I was well into my twenties-amounted to zero. I should also say that even now, after more than 30 years of teaching in universities, the world of education still feels like a borrowed and ill-fitting suit.

The participants were all aware of my university roles; they were also aware that I had grown up very close to where Motorvate UK is located and that my background was not too dissimilar to their own. This is not to throw a blanket of sameness over all participants so much as to recognise a series of shared experiences. My involvement with Motorvate UK is longstanding, working initially on a consultative basis and moving through the years to a more hands-on, workshop and short-course delivery relationship, fitting this work in and around my various academic roles at universities. Given that my subject area is drama, and inasmuch as drama has wide application in the field of youth and community work, incorporating this into the Motorvate UK portfolio was a relatively organic process. Some early success occurred through role-play exercises and, over the years, a number of drama exercises found their way into courses looking at self-confidence, interview techniques, and literacy.

\section{THE PROJECT}

In February 2016, I was invited to set up an ad-hoc gathering of young people who wanted to improve their presentation and literacy skills at the same time as developing their interactions with other people. The sessions ran in the early evenings, once a week, for between one and three hours, depending on the nature of the work we were carrying out and the restlessness of any group members. Nobody was there because they needed to be, there were no credits or awards and often participants would vote with their feet, either not turning up or leaving early. As the weeks went on, participants became more confident, gently assertive and constructively responsive to each other's work. Sessions drew, often very loosely, on Augusto Boal's ideas for forum theatre, with a focus on taking issues from the group members' own lives and playing these out in ways that allowed anybody to stop the action and suggest alternative choices and potential resolutions (Babbage, 2004; Boal, 1982, 1995).

Boal coined the term spect-actors (Boal, 1982, p. xxiii) to describe active spectators who take part in the performed action. Boal stressed the potential involvement of even those who do not physically participate; that is, the invitation to participate is key. Participants are thus able to propose solutions to problems shown to them by other members of the group up to and including replacing one of the actors on the stage area and acting out their own ideas. In Boal's (1995) own words, "Forum theatre consists, in essence, of proposing to 
a group of spectators, after a first improvisation of a scene, that they replace the protagonist and try to improvise variations on his actions. The real protagonist should, ultimately, improvise the variation that has motivated him the most" (p. 184). Another key term Boal deployed was Theatre of the Oppressed (Boal, 1982), which is not something I used with the group, partly because it seemed to have too many negative connotations; certainly, I was focusing in the sessions on opportunity rather than oppression.

In line with Richard Krueger's (2015) suggestions, I kept notes as the sessions went on, writing these up more fully afterwards. Perhaps, at the time I was doing so with an eye on future publication or presentation. If this was the case, it was not something of which I was conscious. The writing felt more like an exercise in narrative, arrived at because writing is the process I go through in order to make sense of the world, or, more accurately, of my own place in the world. I was not consciously focusing on writing that positioned me as an action researcher, although it clearly allowed me to articulate feelings, emotions and external conditions and the particular complexities of my own past and present. In describing the work at Motorvate UK as participatory action research and in my attempts to draw on autoethnography to make sense of it, I am naming reflection as critical to my activities. In this spirit of reflection, a question I am asking of myself and of my own practice is whether I can legitimately turn to these notes, reflections, activities and experiences as a source of research inquiry?

The process of keeping notes allowed me to reflect on the potential benefits of the work we were doing, and where and why this was important. These notes went in my journals, without any consideration of research outputs or of any subsequent writing up. I was making notes purely to enhance the quality of the work done on weekly evening sessions. Nothing was a draft. Nothing was grist to the mill of anything other than the perceived needs of the group. Nothing was about the accumulation of evidence of significance, and yet now I am looking to those same notes in order to produce work in another medium entirely, and to a very different end.

\section{PARTICIPANTS-IN-ACTION/PARTICIPANTS-IN-EXPLORATION}

Dissemination, after all, does not amount to impact and the impact of the work in Coventry was designed for the participants in the moment rather than for any of my academic colleagues. Whilst it is not possible to know in advance the impact of this particular article about work with young people in a UK city, nor to pre-judge the extent to which it might inspire and evoke useful questions in its readers, it is fair to say that the original activity was not entered into with a view to the production of an article. This is not to discredit the value of publishing ideas in journals. Conversation with each other is the heart of academic research in that we learn from each other, and in so doing, bring that learning into our research.

Throughout the workshop process, I wanted to know what would happen next to the people I worked with. I wanted to know what, if anything, they might do differently as a consequence of our sessions, particularly in terms of the employability and/or return-towork aspects that the workshops were intended to address. I needed to ask myself then, as 
now, what impact I was hoping the workshops would have? What impact I was looking for? Research, especially through drama, evokes and provokes unexpected outcomes, and I was hoping to do more than listen to the things I wanted and even expected to hear. Participants filled out response forms during and after the project and their comments are available for me to use, potentially at least and heavily anonymised, in any future writing up of what took place. Referring to this information, however, is something of a corruption of focus, if not quite intent. I know that what I am writing here is likely to be of little or no benefit to the project's participants, even if some of it is of benefit to other readers. The article is informed by research, and it speaks to a set of circumstances that are unique. There is value here, but how many ends can an experience be made to serve, and in whose ultimate interest? Prestige, recognition, and career-enhancement are in the mix more often than I might care to admit, and if the notion of publication for the greater good, of contributing to a world beyond oneself in forums of original research is an admirable aim it is also, I suspect, not always the driving force behind what I do.

Entered into as it was beyond the usual parameters of action research, arguing the cause, effect and impact of the project, as I would expect to do to lend academic weight to the work would be no simple matter. The work sat outside of my usual university practice. I approached the project according to ethical principles I was familiar with and which adhered to the codes of practice common within the organisation; at the same time, I did not run the work through any ethics committee. I was making no bid for funding and, significantly, I was not positioning myself as an action researcher (drawing on my university experience) so much as a workshop facilitator (drawing on my experience of community drama). There were no rigorously policed trials undertaken. Nobody had a particular eye on my work and what went on was unmonitored. If this suggests a narrow reading of action research, or research through action, it speaks too to my concerns apparent by now within these pages - of intent and value.

One of the key principles that underpin ethical action research is the idea that the process is about much more than collecting information. It needs to possess and demonstrate a full concern with the dignity, rights and well being of all participants, and it needs to be upfront about intent. In other words, there needs to be disclosure that is full and overt. I am satisfied that there was no conscious attempt to deceive participants, but it seems now that I may have been engaging in covert research; covert even to me.

\section{CUI BONO?}

Lenza (2004) and Farrimond (2013) might regard this conundrum as broadly legitimate inasmuch as I might claim any such deception was carried out in the service of increased social justice and an increase in knowledge. The most basic premise of ethical behaviour and something that is at the heart of any participatory project is informed consent; i.e. that one's participants are aware that they are part of a research process and that they are aware of what that research intends. I wonder at this point whether it can ever be enough to seek consent after the event. My writing up of sessions reads now as engagement with autoethnography inasmuch as I was creating a document exposing and exploring my emotional experiences at the same time as it helped me make reflective sense of the 
participants' motivation and the ways in which their emotional and often disenfranchised experiences shaped it. I can see now that my approach chimes clearly with Méndez and Peña (2013).

Having written fairly extensively on action research and autoethnography, it may appear gauche to claim now that my intentions at Motorvate UK did not include using work undertaken there to fuel words here and, potentially, on platforms that will reveal more about what went on. And gauche it may be. However, in the years I have spent working with the organisation these are the first words for print that I have ever written about anything that has taken place there. That can appear now like a neglected opportunity. Certainly, the practice of writing up work with socially disadvantaged groups has endless precedents, at times laced through with dubious intent; and yet the very act of keeping things separate, of doing something that brought no financial or professional reward compared to my academic life felt so right as to need no soul-searching. There was no potential conflict of interest, because the interests felt so far apart: a separation that has been bridged by both time and reflection.

The ethical principles relating to both action research and autoethnography have to begin and end with the notion of beneficence rather than maleficence; with protecting the safety and dignity of all participants. Within this approach we afford ourselves some wriggle room precisely because exploitation differs from safety. It is axiomatic that we should not deceive our subjects, neither should we fabricate evidence. Within this, the key questions it seems to me are whether the research is really necessary; and who benefits from that perceived necessity; and who determines it? How might we write ethically? How might we write ethically at the same time as we remain true to the imperatives of narrative trajectory and a reader's requirements? And how, come to that, might we reconcile doing with subsequently writing about. It is in and through this writing about that I am able to engage in critical reflection of my practice as I ask questions, of myself and also now of the critical community this article is part of, for clarification or explanation. In this, I hope to learn about education from thinking about life, and to learn about life from thinking about education (Clandinin \& Connelly, 2000).

\section{CONSENT AND COERCION}

If I tell my own story about the work at Motorvate UK I am almost certainly implicating other people in my tale. I can change names and details, but if an account is really autoethnographic then the people I worked with are potentially, if not explicitly, identified. And if or when I come to write about the work, how fine might the line between anonymity and authenticity become? How many strategies of disguise might I employ before the text becomes a fiction based on fact? What then are the ethics of autoethnographical writing?

We might generally assume an empathetic relationship between the researcher and the researched to the extent that all participants become co-researchers; inasmuch as empathy can be regarded as the ability and intent to respect, understand and give additional voice to another person's point of view. If the opposite of empathy is disinterest, its trap is exploitation, taken here to mean the use of a research subject's experience for our own 
professional gain. If the former demands a critically controlled type of self-awareness, the latter leaks out a sense of self-interest. In working within an ethical frame we need to be aware of our responsibilities to the voices we represent and we need to make sure to question the impact of the decisions we make. Ethical autoethnography is a conversation between ourselves and the text, as well as between ourselves and the selves we describe. It is a conversation between the writer and the written-about. Judging the extent to which we are doing this in good faith and with good intent is a matter of judgement rather than regulation.

What do I feel an action researcher is? All teachers take notes inasmuch as notes amount to reflection in order to plan future actions. When I position what took place at Motorvate UK as action research I am doing so because the reflective participation and decision-making was shared with the project's participants, because there was participant agency and because my way of being within the work was iterative. Notwithstanding the drama focus, my role was not directorial. As participants we were actively engaged in reflecting and deciding the next steps in our project's journey. Inasmuch as the project was not about the ego of the researcher, what we engaged in felt and still feels like action research. My concern here is not to wrestle with the particularly nuanced roles of leader/facilitator/colearner/guide/expert/novice as they occurred within the project, so much as to question whether developing that shared work into any potentially sole-authored outputs might be as much about my sense of ego as it is about sharing practice.

For action researchers, informed consent usually demands the use of the three Cs: it is clear, using plain language with the aim of being understandable and jargon-free; it is concise, keeping to the necessary information; and it is continuous, ensuring that participants are happy to maintain their roles within the process. Other words can be used: collaboration, communication, comradeship, choice and care, and these are words we might be proud to use about our work; but might it be useful for us to consider a less positive C-word, one we rarely acknowledge in our own practice? Might we also consider coercion? The imperative of informed consent is that individuals are assumed to have freely consented to participate in a project; they have to have been given the choice to participate or not and this choice needs to be informed by the fullest information at hand. A large part of this means resisting the assumption that potential participants will fully and/or easily understand what is involved in any given project. My professional life is about communication. It is also, perhaps, and perhaps more than I would usually like to acknowledge, about forms of articulate coercion. A pitch to a publisher, a funding bid, making a case for a sabbatical. Each of these and more are premised in part at least on persuasion.

Knowing that, how difficult might it be to persuade a group of low-income, low-status and out-of-education young people to give their consent for me to write about what happened in our sessions? In wondering now whether to write about what has already taken place, am I able to sidestep the type of questioning I might have faced from an action research ethics board? The answer to the first question is that it was not difficult at all; the answer to the second question is a straightforward yes. The possibility of wrapping my findings up 
within an autoethnographic frame makes things at once a little easier to do and a lot murkier for any outside agency to control.

\section{THE AUTOETHNOGRAPHIC LURE}

Autoethnography has no specific rules or criteria to adhere to since it can be approached through diverse routes. Due to its particular characteristics, the reactions to a personal narrative cannot be foreseen and any interpretations may be varied. Having moved beyond concepts of positivism and neutral observation, researchers are aware that we "can never do more than describe, with all descriptions equally valid ... (Any) researcher can do no more than describe his or her personal experiences" (Neuman, 1994, p. 74). Dissemination is increasingly viewed through the lens of alternative ways of reaching out to multiple audiences. My hope is that I am not trying to take a double-bite out of an activity so much as working through ideas in the hope that the public-facing nature of this article will encourage other people to question their own practice, as well as their own reasons for opting for the dissemination choices that they do.

For Kristina Medford (2006), the thing that matters most is "the criteria by which we evaluate ourselves as we write" (p. 861). Medford (2006) urges autoethnographers to take it as read that the people worked with "might disagree with our representation of shared experiences or they might question our decision to write about an experience in the first place, but we should be willing to confront these issues, even when avoiding them by quietly publishing our work in academic journals" (Medford 2006, p. 862). The idea that any piece of research should have a beneficial or practical goal for all the people involved in it is eminently reasonable; There are examples, not least Carolyn Ellis' own notorious work with the Fisher Folk, where this has clearly not been the case (Roller, 2018), although failure can be just as instructive as an opportunity for learning.

The UK'S Research Excellence Framework assesses the impact of research outside of academia in terms of the work's effect on, change or benefit to the economy, society, culture, public policy or services, health, the environment or quality of life. The work carried out with Motorvate UK is clearly possessed of impact potential, and much of this is verifiable. To say that I have no doubt that I understood and managed the expectations of the group I worked with would be to say more than I fully believe, but I am able to say that the workshop sessions felt like constructive and pleasant places to be and that the various indications from the people I worked with confirmed this. I believe that the sessions delivered tangible benefits in ways that were and which remain sensitive to the social, personal and cultural contexts of all involved; I am satisfied that as the sessions developed I was increasingly able to identify risks and assumptions; that I was prepared to adapt to changing circumstances; and that I facilitated workshops and organised engagement effectively and in good faith. Experience is not the same thing as expertise; nevertheless, I was able to draw on my own long-standing experience of using drama for youth, social and community work, from being employed by Merseyside Arts in the late 1980s through to working with disadvantaged groups in Eastern Europe, Western Australia and in numerous prisons, applied and community contexts in the UK. 
The majority of participants developed the capacity to access knowledge and resources that, whilst being previously available, were not considered part of the participants' world. They started using libraries, began to look into a return to education, even staged their own forum theatre event, inviting friends and family members to attend and participate. Moments like these created additional evidence of sometimes-unexpected impact as and when it arose. I was able to observe changes in attitudes that were underpinning previous behaviours. Despite all of this, the sessions were not firing magic bullets. Not everybody stayed, not everybody engaged, not everybody benefited in tangible ways. The realities of life outside these sessions were grim, and at times all I was able to cling to was that we were creating a safe, respectful space for people to articulate their own experiences without fear.

Colleagues at Motorvate UK have reported evidence of changed behaviours in terms of the way that those participants who have maintained contact with the organisation think, talk and act about issues at a societal scale; about changes in the capacities of individuals to be more resilient and cope better with challenges when they arise, for example, reliance on drugs, anti-social behaviour and feelings of hopelessness. In the context of these colleagues and in order to maintain a sense of ethical balance it is important to point out that the work I engaged in with participants was not the only contact any of them had with Motorvate UK.

The word 'ethical' is as complex as any other, and even if we side with Foucault's notion (O'Leary, 2002) that to be ethical in print is to inform freedom with reflection, to consciously reflect on the worlds we are representing, I am still using language to persuade readers of a personal point of view. No bad thing in something overtly fictional, but what of the ethics of autoethnography?

Addressing the ethics of writing narratives that consider what happened means asking ourselves some questions; and the way we answer these determines how we view our work's ethical quotient. We have to ask whether it is possible to make any watertight distinctions between autobiography, autoethnography and story, and whether different forms carry different ethical responsibilities. We have to ask what experiences any one person can say truly and exclusively belong to them; we have to wonder whether observation through action research or any form of research can so change the event being studied that it loses its a priori currency; we need to know the extent to which a person can give or withhold the rights of any others to tell their stories, or stories they might feel are very culture-specific; we need to know whether the essence of somebody's identity or experience might be privileged to the extent that others are prevented from writing it. We read and speak often enough about the rights that certain people have or do not have to tell certain stories, and we need to know whether, in the context of our own work, these beliefs hold true.

When I asked permission of the participants I worked with to write about what took place, how knowingly and deliberately persuasive did I set out to be? Did I give the participants enough licence to refuse? Having built up a relationship with them over several months 
were their responses coloured by that? In short, did I behave ethically, and am I doing so now?

\section{AN ETHICAL JUDGEMENT, OR A JUDGEMENT OF ETHICS?}

For sure, I undertook the work based on empathy. I feel a sense of kinship with Coventry, which means that I would always be more likely to engage in voluntary work there than elsewhere. The relationships that developed through the work were not based on any idea of the researcher and the researched. Had there been, I might have been safe to assume an empathetic relationship, inasmuch as empathy can be regarded as the ability and intent to respect, understand and give additional voice to another person's point of view. In this context we can say that empathy allows the researcher (or as I was, a project-leader) to articulate significant ideas about the researched other (the project's participants) and the researcher's self (me then and me now). What then of this article, where the permission I have been granted to write does not mean that I am at all convinced that I should, and where regulation and judgement are slightly misaligned?

Judgement comes too in the number of critical and contextual terms that I could draw upon to lend an air of enhanced legitimacy to my work. I might refer to the work as a form of autopsychography, an account of my development, a self-narrative form that tracks my lived experience of the project, focusing on changes in me rather than in participants (Yuan \& Hickman, 2016); I could locate myself as an artist-teacher, as someone who deploys artistry in the connected fields of community practice and education; I could describe the project in terms of $a / r /$ tography, a term that holds the identities of teacher, researcher and artist together as something holistic and inseparable (Springgay, Irwin \& Wilson Kind, 2005). Drawing upon Rebecca Heaton's arguments, the project could be positioned significantly as the practice of teaching and learning, of my relational experience and subsequent response to the work (Heaton, 2018). My writing up could summarise the ways in which the project re-connected me to a community I am no longer a permanent part of, but would doing so locate me as someone who sees research activity wherever he looks, like a zealot seeing the face of Christ in a slice of burnt toast?

\section{The Dubious Value of I}

For Richardson (1994) writing is a "method of inquiry, a way of finding out about yourself and your topic. Although we usually think about writing as a form of "telling" about the social world ... writing is also a way of "knowing", a method of discovery and analysis. By writing in different ways, we discover new aspects of our topic and our relationship to it. Form and content are inseparable" (p. 7). Sparkes (1996) aligned himself philosophically with autoethnography and connected the personal with the cultural when he said, "I ... attempt to take you as the reader into the intimacies of my world. I hope to do this in such a way that you are stimulated to reflect upon your own life in relation to mine" (p. 467).

We bring who we are to what we do and we teach who we are. Nevertheless, let us accept, for the sake of argument, that I was neither positioning nor considering myself as either action researcher or autoethnographer at the time of the project and the significance of what took place there has only recently registered to me as externally noteworthy, 
inasmuch as I have come to believe that the experience could be valuably articulated in print; i.e. it has become research-noteworthy only in retrospect. Let us assume too, for the sake of argument that this writing up of what the project did and of what it might achieve (when and if this writing up happens) is crafted in such a way as to make its contents useful to a community of interested scholars and those who engage with young people in similar circumstances. Under those circumstances, am I appropriating from a particular culture for my own ends? A reasonable definition of cultural appropriation, and one that Bruce Ziff posits, is "the taking - from a culture that is not one's own - of intellectual property, cultural expressions or artefacts, history and ways of knowledge" (Ziff \& Rao, 1997, p. 48). Of the participants I regularly worked with, seven were of West Indian descent, two were born in Poland, two were Somalis and one was from Iraq. Inasmuch as Roth reminds us that autoethnography has to focus on what we have in common with others, this is a good time perhaps to explain something of my own background (Roth, 2008). My name, John Freeman, does not tell the whole story of who I am. My father was adopted; a fact I was unaware of as a child. My father's birth name was Hannon; he was born in the Irish Republic, in Waterford. The man who had adopted my father was a professional magician, Paul Freeman, a Londoner from Russian parents. My father's natural parents had died when he was young. My natural grandfather, Michael Hannon, was a traveller, a tinker, a gypsy. His wife, my grandmother, was also from travelling stock.

My mother's father was Armenian. His given name was Gachig, or Gakig. We called him Gach. My mother's paternal grandparents had each been killed, massacred, not long into the 1st World War, when Turkey began a process of deporting the Armenian population to Mesopotamia and Syria. Between 500,000 and 1.5 million Armenians were murdered or died of starvation during this period. My great grandparents died, as near as anybody can tell, in 1915. Their bodies were never found, never buried and, in the madness of the time, and according to the version told by Gach, barely mourned. The Armenian massacre was the first genocide of the 20th century. My maternal grandmother, Nancy, was a Canadian. She fell pregnant to Gach after meeting him on a journey by boat to Scotland. Nancy was fleeing her Canadian husband. Who now knows why? Nancy and Gach disembarked and rented a house together in Glasgow where Gach worked as a pianist and Nancy a seamstress. They subsequently married, making Nancy a bigamist. As a boy I had no idea of any of this. As a man, seeing how different my mother looked from her siblings, all younger and all but one deceased, I wonder if my grandmother carried my mother inside her when she boarded her ship and whether that portion of my blood that might be Armenian is Canadian.

I knew Paul Freeman as my father's father; I knew Gach as a dark-skinned Scot with a complicated accent. Brought up in England I was surprised to learn that there is not one drop of English blood in my veins. My mother, either conceived on the ocean and born in Scotland to a husband-fleeing Canadian and a nomadic Armenian or fathered by a Canadian whose details are long lost to time; my father the Irish son of dead travellers. My parents met in Brighton, at a hotel facing out to the sea, as workers there rather than guests. Does this decidedly non-UK heritage, give me some additional empathetic licence? And what, come to that, is my culture? How tenuous, or distant, or heartfelt need my links to a cultural 
group be before I fall beyond the parameters of Ziff's definition? Can I write about Canadians and bigamists, Armenians and travellers and can I do so without censure? Can I write about the victims of genocide in a way that locates me as a kindred victim? Can I? Should I? Does the blood in my body override the fact that I feel more or less English? Does it make me an outsider? Does growing up dirt poor in a violent environment grant me further licence, so that who I am (whoever that is) gives me a get out of ethical jail card?

Should I go further still in my attempt to position myself as more inside the group I worked with than outside, despite differences in age and income and status? Should I articulate something of my earlier and non-professional, non-academic life, a life just about as far removed from the one I currently enjoy as it is possible to imagine? Should I make public and dwell upon formative hardship: of beatings and poverty and evictions, of failings and loneliness, picking at the scars of experience until they open into wounds where blood serves as a type of ink? Should I, in the spirit of Bryant, Moreira and Kumar's (2012) triautoethnographic exploration, delve deeply into my combative relationship with my late father? There were risks involved in my participation in the project. It is not uncommon, for example, for fights to break out between the people who use the Motorvate UK facilities and members of staff have themselves been victims of assault. As there were risks there, so are there here, and also in any writing-to-come. Revealing aspects of my earlier life amounts to a type of disclosure that carries a certain risk. Despite the fact that I am not operating with any sense of full disclosure, I am nevertheless disclosing things about myself that I would not ordinarily want colleagues to know. Am I holding some things back that would strengthen the work for fear those same things might weaken my professional position? Generally speaking, where researchers intend to reveal sensitive information about themselves, they are advised to implement safeguards to protect their own confidentiality (Ryerson, 2018). Should I eschew this advice and explain how I got from benefits offices, factory floors and building sites to university common rooms and from London to West Australia and back again via a stint in California? Should I write about friendships kept and enemies made and relatives lost? Should I acknowledge and accept, as Barton (2012) suggests in regard to her own work, that almost every element of one's life becomes data to be subsequently used?

\section{IDENTITY AND IDENTIFICATION}

Ultimately, I think and hope that not everything we have lived through can be brought out, dusted off and made into a case for a kind of sometimes-dubious empathy. I hope too that the blurred line between being empathetic and exploitative is less about identity than integrity; that it negotiates a reckoning with different and potentially difficult perspectives; that it involves people who are where they are and who think what they think, rather than being where researchers think they should be and thinking and behaving in the ways that most profitably suit our professional ends.

The intention behind autoethnography is that narratives are constructed through the interaction between people and the place in which they live (Silverman, 2000). According to Denzin and Lincoln (2000), autoethnographers "study things in their natural settings, attempting to make sense of, or to interpret, phenomena in terms of the meaning people 
bring to them" (p. 3). In a narrow sense, personal experiences and narratives become data for researchers to find the answers they are looking for. This is an assumption that certain researchers come with an agenda that is solutions-orientated rather than curiosityoriented. In a broader (I might say better) sense, researchers seek and find questions they had never imagined. Autoethnography is thus used as a means to read people's lives, a process that Ellis and Bochner (2000) described as "an autobiographical genre of writing that displays multiple layers of consciousness, connecting the personal to the cultural" (p. 739). The core feature of autoethnography is that it is never just writing about oneself; rather it is the creation of a text which uses criticality about personal experiences in order to develop a further insight into the research being undertaken; to shed new light on the topic being investigated.

Perhaps this article is a plea for what Roberts (2018) describes as the 'researcher-asbricoleur', as someone who goes about their work without a specific methodological strategy. Kincheloe (2005) reminds me that bricolage, a multi-method mode of research, exists out of respect for the complexity of the lived world; that it is based on an epistemology of complexity, constructing a far more active role for humans both in shaping reality and in creating the research processes and narratives that represent it. Perhaps the article is a questioning of the extent to which we need to trust the teller before we trust the tale; certainly, the text of this article as I read it now feels confessional, despite the fact that all (?) it has exposed are my own concerns about doing the right thing, or of doing the things right. Perhaps too it is acknowledgment that persuasion if not always coercion is front and centre in so much of what I do professionally that notions of being on the inside or outside of a project have come to feel like an exercise in word-play.

Deborah Reed-Danahay (1997) asks whether the autoethnographer is an insider or an outsider of the phenomenon being described. She asks whose voice is being heard: who is speaking, the people under investigation or the researcher? The fact that these are good questions does not make them necessarily any easier to answer. In my case, am I an outsider? Clearly I am. I do not live where my participants live (although I did); I do not share the low expectations they joined the sessions with (although, as a young man my expectations were low in almost all spheres); I work in education, the sector they have largely been excluded from (although I too was excluded, suspended from secondary school for long periods); I am not out of work (although at the age of most of the project's participants, I was). An outsider I am, but one whose background allows me a connection I might not otherwise have. And whose voice is being heard here?

That the voices of the participants I worked with are excluded from this article does not make them entirely absent and nor does it make them an afterthought. But would the article carry more weight, or carry it differently if their words were included here, as they would be and as they will be if I choose to write about that work, rather than writing here about writing about it? If the participants' anonymised words were the first thing readers came upon, or if they were woven through the paragraphs as a reminder of who the work was with and for, would the article be better received? Would doing that be an act of inclusivity or a writerly trick? I could write in this way, interweaving my own ideas, 
questions, concerns with the inclusion of their voices as a writerly exercise of integrity, but would such an approach honour the relationships and work engaged in through the workshops? And if a particular kind of inclusion is designed to do no more than salve my own conscience at the same time as it tries to seduce the reader, what would be its claim for authenticity and what would be its gain? Or is the decision to make visible the ethical quandaries that trouble me valuable for researchers who engage in participatory action research and/or autoethnography?

Were this article the end-result of a fully formed action research project then the predominance of my voice might be troublesome, but this article is not that. This writing is not so much an attempt at imbuing a process with validity in the eyes of my academic colleagues so much as a questioning of where validity and value lie and the extent to which we might shape what we do into what we want. In a context such as that, whose voice can I ask that question with but my own?

\section{REFERENCES}

Babbage, F. (2004). Augusto Boal. London \& New York: Routledge.

Barkhuizen, G., \& Wette, R. (2008). Narrative frames for investigating the experiences of language teachers. System, 36, 372-387. http://dx.doi.org/10.1016/j.system. 2008.02.002

Barton, B. (2011). My auto/ethnographic dilemma: Who owns the story? in Qualitative Sociology, 34, 431-445.

Boal, A. (1982). The theatre of the oppressed. London \& New York: Routledge

Boal, A. (1995). The rainbow of desire: The Boal method of theatre and therapy. London \& New York: Routledge.

Bryant, K. A., Moreira, C., \& Kumar, H.S. (2012). Resisting (resistance) stories: Exploration of father narratives across shades of difference. Qualitative Inquiry, 18(2), 121-133.

Carr, W., \& Kemmis, S. (1986). Becoming critical: Education, knowledge and action research. The Journal of Educational Thought (JET) 23(3), 209-216.

Clandinin, D.J., \& Connelly, F.M. (2000). Narrative inquiry: Experience and story. Qualitative Research. San Francisco: Jossey-Bass.

Connelly, F.M., \& Clandinin, D.J. (2006). 'Narrative Inquiry'. In: Green J, Camili \& G, Elmore P (Eds.), Handbook of Complementary Methods in Education Research. Mahwah, NJ: Lawrence Erlbaum, 376. 
Creswell, J.W. (2007). Qualitative inquiry and research design: Choosing among five approaches, 2nd edition. Sage Publications.

Darby, S. (2017). Making space for co-produced research "impact": Learning from a participatory action research case study. Area 49, 2, 230-237.

Denzin, N.K., \& Lincoln, Y. S. (2000). Introduction: The discipline and Practice of Qualitative Research. In N. K. Denzin \& Y. S. Lincoln (Eds.), Handbook of qualitative research. 128. London: Sage.

Ellis, C. (2007). Telling secrets, revealing lives: Relational ethics in research with intimate others. Qualitative Inquiry.

Ellis, C., \& Bochner, A. P. (2000). 'Autoethnography, personal narrative, reflexivity: Researcher as subject'. In N. K. Denzin \& Y. S. Lincoln (Eds.), Handbook of Qualitative Research. 733-768. London: Sage.

Farrimond, H. (2013). Doing ethical research. Basingstoke: Palgrave.

Flick, U. (2009). An introduction to qualitative research, Edition 4. London: Sage.

Hamilton, M. T., Healy, G. N., Dunstan, D. W., Zderic, T. W., \& Owen, N. (2008). Too little exercise and too much sitting: Inactivity physiology and the need for new recommendations on sedentary behavior. Curr. Cardiovasc. Risk Rep, 2, 292-298. doi: $10.1007 / \mathrm{s} 12170-008-0054-8$

Hamilton, M.T. \& Pinnegar, S. (2009). Self-study of practice as a genre of qualitative research. Theory, Methodology, and Practice. 10.1007/978-1-4020-9512-2.

Heaton, R. (2018). Autoethnography to artography: An exhibition of cognition in artist teacher practice. https://doi.org/10.17863/CAM.33324

Jousse, M. (2000) The anthropology of geste and rhythm. $2^{\text {nd }}$ revised edition. Durban: Mantis Publishing.

Kincheloe, J. L. (2005) On to the next level: Continuing the conceptualization of the bricolage. Qualitative Inquiry. Vol. 11(3), 323-350.

Krueger, R. (2015). Focus groups: A practical guide for applied research. Singapore: Sage

Lenza, M. (2004). 'Controversies surrounding Lau Humphrey's Tearoom Trade: An unsettling example of politics and power in methodological critiques. Journal of Sociology and Social Policy, 24, 20-31. 
Maso, I. (2001). Phenomenology and ethnography. In P. Atkinson, A. Coffey, S. Delamont, J. Lofland and L. Lofland (Eds.), Handbook of Ethnography. London: Sage.

Medford, K. (2006). Caught with a Fake ID: Ethical questions about slippage in autoethnography. Qualitative Inquiry, 12, 853-864.

Méndez, M.G., \& Peña, A. (2013). Emotions as learning enhancers of foreign language learning motivation. PROFILE, 15, 109-124.

Mooney, R. (1957). 'The researcher himself'. In Research for Curriculum Improvement. Washington, DC: Association for Supervision and Curriculum Development. 1957 Yearbook (pp. 154-186).

Neuman, L. (1994). Social research methods: Qualitative and quantitative approaches. Boston: Allyn and Bacon.

O'Leary, T. (2002). Foucault and the art of ethics. London: Continuum.

Pennebaker J.W., \& Seagal, J.D. (1999). Forming a story: The health benefits of narrative. Journal of Clinical Psychology, 55(10), 1243-1254.

Pithouse, A., Hall, C., Peckover, S., \& White, S. (2009). A tale of two CAFs : The impact of the Electronic Common Assessment Framework. British Journal of Social Work, 39(4), 599-612.

Reed-Danahay, D. E. (1997). Introduction. In D. E. Reed-Danahay (Ed.), Auto/ethnography: Rewriting the self and the social. 1-17. Oxford: Berg.

Richardson, V. (1994). Conducting Research on Practice. Educational Researcher, 23, 5-10.

Roberts, L. (2018). 'Spatial bricolage: The art of poetically making do.' Humanities, 7(2). https://www.mdpi.com/2076-0787/7/2/43

Roller, M.R. (2018). To deceive ... or not? Research Design Review. https://researchdesign review.com/2013/06/30/to-deceive-or-not/

Ryerson University Ethics Board. (2018). Guidelines for Conducting Autoethnographic Research. https://www.ryerson.ca/content/dam/research/documents/ethics/ guidelines-for-conducting-autoethnographic-research.pdf

Roth, W-M. (2008). Auto/ethnography and the question of ethics. Forum Qualitative Sozialforschung/Forum: Qualitative Social Research, 10(1), Art. 38. http://nbnresolving.de/urn:nbn:de:0114-fqs0901381 
Sienaert, E. (1990). Marcel Jousse: The oral style and the anthropology of gesture. The Oral Tradition, 5(1), 91-106.

Silverman, D. (2000). Doing qualitative research: A practical handbook. London: Sage.

Sparkes, A.C. (1996). The fatal flaw: A narrative of the fragile body-self. Qualitative Inquiry. 2(4), 463-494.

Springgay, S., Irwin, R., \& Wilson Kind, S. (2005). A/r/tography as living inquiry through art and text. Qualitative Inquiry, 11(6), 897-912.

Stoller, P. (1997). Sensual scholarship. Pennsylvania: University of Pennsylvania Press.

Toledano, N., \& Anderson, A. (2017). Theoretical reflection on narrative in action research. Action Research, 15(4). https://journals.sagepub.com/doi/full/10.1177/ 1476750317748439

Whitehead, J. (2004). What counts as evidence in self-studies of teacher education practices? In J. J. Loughran, M. L. Hamilton, V. L. LaBoskey, \& T. L. Russell (Eds.), The international handbook of self-study of teaching and teaching education practices, 871-904. (Springer International Handbooks of Education; Vol. 12). Netherlands: Springer.

Yuan, Y., \& Hickman, R. (2016). "Autopsychography" as a form of self-narrative inquiry. Journal of Humanistic Psychology. (August).

Ziff, B., \& Rao, P. (Eds.). (1997). Borrowed power: Essays on cultural appropriation. New Jersey: Rutgers University Press.

\section{BIOGRAPHICAL NOTE:}

John Freeman is Senior Lecturer in Performance at the University of Huddersfield and Adjunct Professor in the School of Arts \& Sciences at the University of Notre Dame Fremantle. A Fellow of the Royal Society of Arts and the Higher Education Academy, he has written extensively on memory, autoethnography and performance in a series of books and articles. 